\title{
MICROORGANISMS IN ALIMENTATION: THE LABORATORY DIDACTICS IN THE TEACHING - LEARNING PROCESSES OF LIFE SCIENCES IN PRIMARY SCHOOL
}

\author{
Chiara Pavan ${ }^{1}$, Marta Bellio ${ }^{2}$, Francesca Corrà ${ }^{3}$, Marco Bonato ${ }^{4}$, Sophia Schumann ${ }^{5}$ \\ Paola Irato $^{6}$, Gianfranco Santovito ${ }^{7 *}$ \\ ${ }^{1}$ Dr, University of Padova, Italy, ilary110zando@gmail.com \\ ${ }^{2}$ Dr, University of Padova, Italy, marta.bellio@unipd.it \\ ${ }^{3}$ Dr, University of Padova, Italy, francesca.corra@unipd.it \\ ${ }^{4} \mathrm{Dr}$, University of Padova, Italy, marco.bonato@unipd.it \\ ${ }^{5} \mathrm{Dr}$, University of Padova, Italy, sphia.schumann@studenti.unipd.it \\ ${ }^{6} \mathrm{Dr}$, University of Padova, Italy, paola.irato@unipd.it \\ ${ }^{7} \mathrm{Dr}$, University of Padova, Italy, gianfranco.santovito@unipd.it \\ ${ }^{*}$ Corresponding Author
}

\begin{abstract}
This study falls into the field research of Life Science didactics. According to the main Italian (Italian Guidelines for the Curriculum in the Primary School - 2012 Edition) and European law documents (Recommendation of the European Parliament and of the Council, 18 December 2006), and to the scientific research made on the subject, the most effective approach to Live Science teaching seems to be the one that uses laboratory didactics, allowing the student to be active protagonists of their learning.

This work focuses on laboratory didactics and how they, integrated with the traditional teaching methods, could be more valid than the traditional method alone. The subject chosen was Microbiology, in particular microorganisms that interact with food (bacteria that could be beneficial of not for human health and yeasts that could transform food).

In order to try this method, a preliminary investigation was carried out regarding the teaching methods usually adopted by teachers of Natural and Experimental Sciences of the Primary School involved in this research. The obtained results were useful to understand the methods used by the teachers and if the teaching of Microbiology was common. As it turned out, Microbiology and the subject of microorganisms in the alimentation is marginally considered in Primary School and this confirmed the originality of the project.

The project was divided into two teaching phases. The first one regarded the bacteria and the importance of hand-washing before eating, the second one regarded yeasts and how the alcoholic fermentation could lead to processes like the leavening of bread.

In both cases part of the activity was held in the classroom as frontal lesson, and part was in the laboratory, where students (children of the third class of primary school, approximately 8 years old) had the opportunity to work with optical microscopes, culture mediums in Petri's capsules and with the application of the scientific method. Some simple tests were proposed after each activity, in order to verify and compare the efficacy of the two types of didactics.

The results confirmed the initial hypothesis that, in the teaching-learning of Life Sciences, using laboratory didactics is more effective than a traditional approach. The scientific method, used in the experimentation, was very valid for a meaningful learning, and it produced skills that may also be used in other contexts. The use of scientific instruments, such as optical microscope, and techniques, such as microbial culture, gave value to the application of scientific method and kept the students very motivated and interested in the subject of Microbiology. All these activities can be proposed again to other students of primary and secondary school with some adaptations.
\end{abstract}

Keywords: Alimentation, life sciences, primary school, microorganisms, scientific method. 


\section{INTRODUCTION}

Biology is a scientific discipline with specific characteristics that differentiate it from other subjects. It is important to use a particular language and a specific method of inquiry. Great importance is also given to the history of the subject and to the influence that other areas of scientific knowledge have on it. When talking about Biology teaching, it is necessary to broaden the subject to General Science because, in the Italian primary school and in the first cycle of education, Biology is taught as a part of it. Given the few available hours of teaching, it is unthinkable to teach in depth all the aspects of the specific subject. However, it is possible to provide the students with a comprehensive view of the discipline. Particular attention should be given to the teaching of the scientific method, and the best way to do it is thought active teaching in the laboratory.

Longo describes the teaching-learning process as the foundation of active learning when (Longo, 1998): i) the starting point is the daily reality of the students; ii) great importance is given to class discussion; iii) central elements of the teaching are tests with simple experiments, focused observations and field explorations; iv) importance is given to interdisciplinarity and to integration with other school subjects, especially the Italian language; v) the most suitable methodologies integrating various modality of teaching are used; vi) there is a balance between the basic knowledge learned in class and the ability to use it in everyday life; vii) the teaching of the subject stirs up emotions such as: pleasure, motivation to learn, curiosity and interest; viii) multiple channels of expression are developed; ix) There is preferably direct experience in the study of living organisms and environments; $x$ ) There is no hurry to get immediate results.

This approach in teaching can lead the students to acquire meaningful knowledge, but another important factor in the teaching of science is the learning environment that, in this case, is the laboratory. The laboratory is a place where everything makes sense, it is an operational context in which the student can learn Life Science and also other disciplines.

The activities proposed in this research were based on the scientific method. The scientific method consists in the collection of measurable data on a particular phenomenon through observation and experimentation, and the formulation of new hypotheses and theories that need to be verified experimentally. In this type of approach, it is possible to support or refute a hypothesis, but it is essential that the data obtained are carefully collected and that the experiment is repeated until the results are consistently the same.

In this research the experimental method was employed in the activity on bacteria and yeasts. While the observational-comparative method was used for the macro and microscopic observation of different types of microorganisms, especially bacteria, yeasts and moulds.

\section{MATERIALS AND METHODS}

\subsection{Field of Work}

This research involved the classes $3 \mathrm{~A}$ and $3 \mathrm{~B}$ of the Primary School "N. Tommaseo" of the Comprehensive Institute of Trevignano (Treviso-Italy). The class 3A was composed of 16 pupils while the class $3 B$ of 22 pupils. Working in two different classes had both advantages and disadvantages. It was more difficult to manage the organizational aspects, the workload was doubled and the results were different because of the different nature of the two groups involved. However, presenting the same educational activities in different classes in different moments was an advantage because it was possible to utilize and apply what was learnt from the previous experiences.

\subsection{Preliminary Analysis}

Before starting the activities with the students, it was necessary to verify which practices and methodologies were employed by the teachers in the teaching-learning of Life Sciences and of Microbiology in particular. A simple questionnaire was administered to all teachers. The questionnaire was divided in three parts. All the data concerning the personal and professional characteristics of the teachers were collected in the first part. The second part was centred on the educational-methodological choices made by the teachers regarding the teaching of science. The third part was more specific, it asked direct question about the didacticmethodological choices made by the teachers regarding food education and microorganisms, the topics of the experimental activity. Thanks to this survey it was possible to design an original educational plan based on the answers of the teachers.

\subsection{Experimental Phases}

The activities of this project were divided into two steps that are summarized in Table 1. 
Table 1. The steps of the experimental activity

\section{Step 1: Microorganisms, bacteria and hand hygiene before you eat}

\section{Traditional method}

Instruments: a computer; a Power Point presentation of the argument; tests to verify the efficacy of the method used.

Methods: traditional method of teaching.

Activities: investigation on background knowledge; theoretical explanation in class of the main types of microorganisms, especially bacteria, and of the importance of hand washing before eating; verification of the efficacy of the traditional method with a simple test.

\section{Laboratory didactics}

Instruments: some agar plates in Petri's dishes already prepared and functional for the sowing and cultivation of the microbial load found on the hands; an optical microscope for the microscopic observation of cultured microorganisms; water, liquid soap and disinfectant that were used to perform three tests to see the different presence of microorganisms on dirty hands, on soap washed hands and on hands cleaned with a disinfectant; a form of data collection in which it was asked to fill in the tables with the assumptions made by the students and with the data collected by observing the plates after the sowing; a survey form of the data collected from the observation of microscopic organisms in which the students had also to draw what they saw (bacteria and mold); tests for the verification.

Methods: laboratory didactics and scientific method (observational-comparative method, experimental method).

Activities: laboratory experience in the classroom: cultivation of the microbial load found on the hands; reflection on the importance of hand washing before eating, macro and microscopic observation of the microbial cultivation; verification of the efficiency of the laboratory didactics with a simple test.

\section{Step 2: Yeast, proving and fermentation}

\section{Traditional method}

Instruments: a computer; a Power Point presentation of the argument; tests to verify the efficacy of the method used.

Methods: traditional method of teaching.

Activities: investigation on background knowledge; theoretical explanation in class of microorganisms in alimentation, with particular attention to yeasts, alcoholic fermentation and the leavening of bread; verification of the efficacy of the traditional method with a simple test.

\section{Laboratory didactics}

Instruments: an optical microscope for microscopic observation of yeast; some plastic cups to carry out experiments on the fermentation and rising of the bread; water; flour; sugar; fresh yeast to make bread dough; an electronic scale to weigh the bread dough and see if the weight increases due to the rising; bread dough already prepared to show the students that the bubbles of carbon dioxide produced by fermentation are found both inside and outside of the dough; a ruler to measure the height of the dough before and after fermentation; a form of data collection; tests to verify the efficacy of the laboratory didactics.

Methods: laboratory didactics and scientific method (observational-comparative method, experimental method).

Activities: laboratory experience: experiments on the action of yeast in the fermentation and the consequent rise of the bread; macro and microscopic observation of yeast; verification of the efficacy of the laboratory didactics. 


\section{RESULTS}

\subsection{Results of the Preliminary Analysis}

The questionnaire, described in the previous paragraph, has been administered to a sample of 23 Science teachers. The responses show that, for most of them, it would be useful to integrate laboratory didactics with the traditional one. But the problem is that no one uses instruments like microscopes because often at school there are not equipped laboratories.

The results obtained in the research, however, show that the classroom and the available spaces in school may be easily processed and adapted to act as a functional laboratory. Other than stating a preference for integrating teaching with a laboratory activity, most teachers believes that primary school textbooks do not offer enough contents when Science is concerned. However, by virtue of the principle of freedom of teaching, a teacher can choose to teach a topic not present in the textbook, like in this case.

Another question regarded the theme chosen for this activity: the microorganisms in the alimentation, which is not a subject usually studied in class. The reason why this theme is neglected and never proposed in class, even if it is considered useful, is because Science teachers lack a real expertise on the subject and because the school has not the necessary resources.

There is a gap in data of the investigation conducted because many teachers have never proposed the argument, so they could not answer questions regarding this particular modality of teaching. This research, however, has highlighted the usefulness of treating the subject of microorganisms in the alimentation in order to develop a greater awareness on the topic. Teaching active laboratories can also be seen as a way to introduce general aspects of Microbiology. Some conflicting answers were found regarding the actual behaviour of teachers and their educational - methodological approach.

\subsection{Results of the Experimental Activities}

\subsubsection{Results of the First Step: Microorganisms, Bacteria and Hand Hygiene Before You Eat}

The first part of the course was held in the classroom, with a lecture on the general subject of microorganisms, using the traditional method. The lesson was structured by alternating a clinical conversation to questioning to students in order to understand their background knowledge on the subject (questions like: What are the microorganisms? How many types of microorganisms do you know? Where can you find them? etc.). The asking part was very important because it allowed us to modulate the teaching according to their feedbacks. The topics discussed were: a definition of microorganism; the four main groups of microorganisms; bacteria that can be beneficial of harmful to our health; the importance of hand hygiene before eating; the classification of bacteria on the basis of morphology; the size of bacteria; where to find the bacteria (habitats); techniques and tools to observe microorganisms such as bacteria (microbial cultivation on agar plates and microscopic observation of the colonies formed). As it was clear by the lesson, their prior knowledge on the subject was naïve and lacking some basic information, so a big part of the lesson was used to raise awareness about the role of bacteria as carriers of food-borne infections and diseases, but also as beneficial to humans. It was significant to reflect on the distinction between living and non-living organisms because for them bacteria were non-living.

The activities of the laboratory didactics were made in a second moment, and they were significantly important for the reaching of the desired results. Both the classroom and an equipped science laboratory were used for the activity.

Both the scientific and the experimental method were used in all the phases of the activity, we started by observing the hands and wondering if they were clean of dirty. The end of a brief discussion with the students led to the formulation of a hypothesis shared by the whole group. The hypothesis was that, if the hands were clean, there were no microorganisms on them, if the hands were dirty, there were. To confirm or deny the hypothesis it was necessary to carry out a simple experiment. The next step was the introduction of the experiment, that consisted in the planting and cultivation of microorganisms present on the hands of the students. They were divided into small groups and each group had three agar plates where to sow and grow the bacteria of their fingers (Fig.1). 


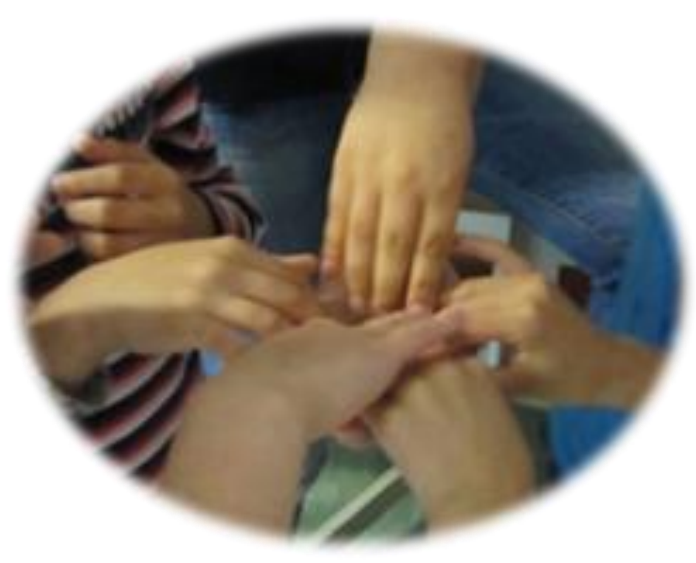

Fig. 1: Seeding of the students' microbial load on agar plates, previously prepared. Agar is the solid medium contained in the Petri dishes full of nutrients in which bacteria grow.

In the first Petri dish they put their unwashed fingers. In the second one the fingers washed with soap and in the third one the fingers cleaned with a disinfectant. After the sowing, the plates were immediately sealed with a film and the children were given the task of observing them in the next days to see what happened and to record the data.

As easily predicted, in the Petri dish sawn with dirty hands, not only bacteria did grow, but also other types of microorganisms. In fact, in addition to bacteria such as Staphyloccus aureus, easily recognizable by the golden colour of its colonies, and some colonies of Serratia marcescens, bright red in colour, many moulds were recognizable, of various types and colour (Fig.2).

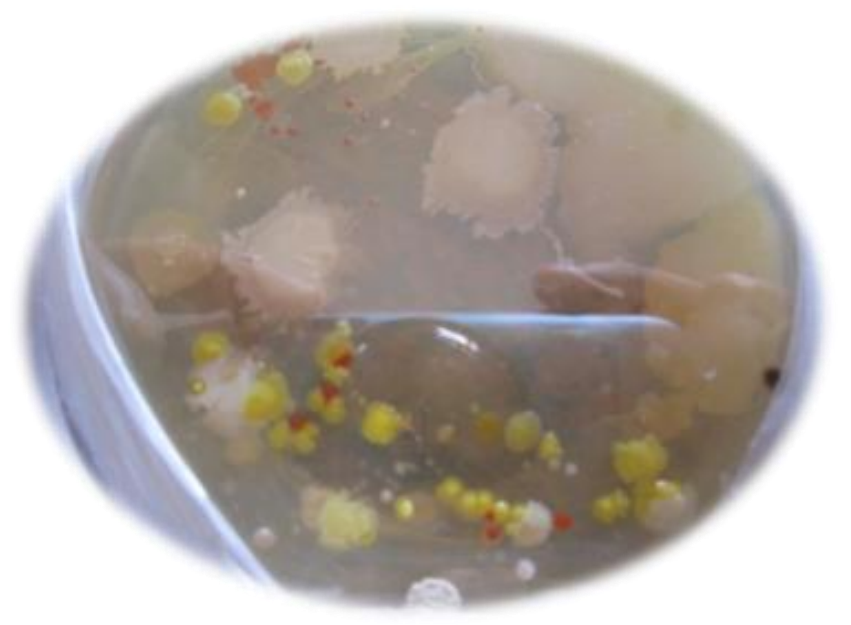

Fig. 2: Microbial load present in a plate grown by the students in which there are grown recognizable colonies of Staphylococcus aureus (golden colonies), Serratia marcescens (red colonies) and various types of moulds.

These results were the ideal basis to explain to the children that on their hands there are different types of microorganisms, not only bacteria, and that these organisms could be observed under the microscope. After the activities, the students completed a questionnaire on the experience. As it turns out, most of them did not expect to see so many bacteria after only one day. They thought that a few days were required. They noted how the microbial load was different in the three different petri and that meant that, the dirtier the hands, the more microbes were present and, therefore, they understood the importance of hand washing to reduce the presence of microorganisms.

The final part of the experiment consisted in the observation of the microorganisms with the optical microscope. A small sample of microorganisms (bacteria) was taken from the agar plate, and, after a dilution with water, it was smeared on a slide and covered with a coverslip. To observe the moulds, it was sufficient to place the plate under the lens.

Through careful observation and using the observational - comparison method, the students were able to understand the similarities and differences between these two types of microorganisms. For example, they understood that both bacteria and moulds are organisms, that they are very small in size and invisible to the 
human eye, but they belong to two different groups. Moulds in fact, belong to the realm of fungi, not of bacteria. Pupils were also given a card to collect data on which they were able to gather some information from the observation and draw a picture of what they saw. An analysis of the children's drawings showed that all bacteria were represented in the form of tiny dots, barely visible under the microscope and not as large anthropocentric animals like the one they drew in the class before the experiment (Fig.3).

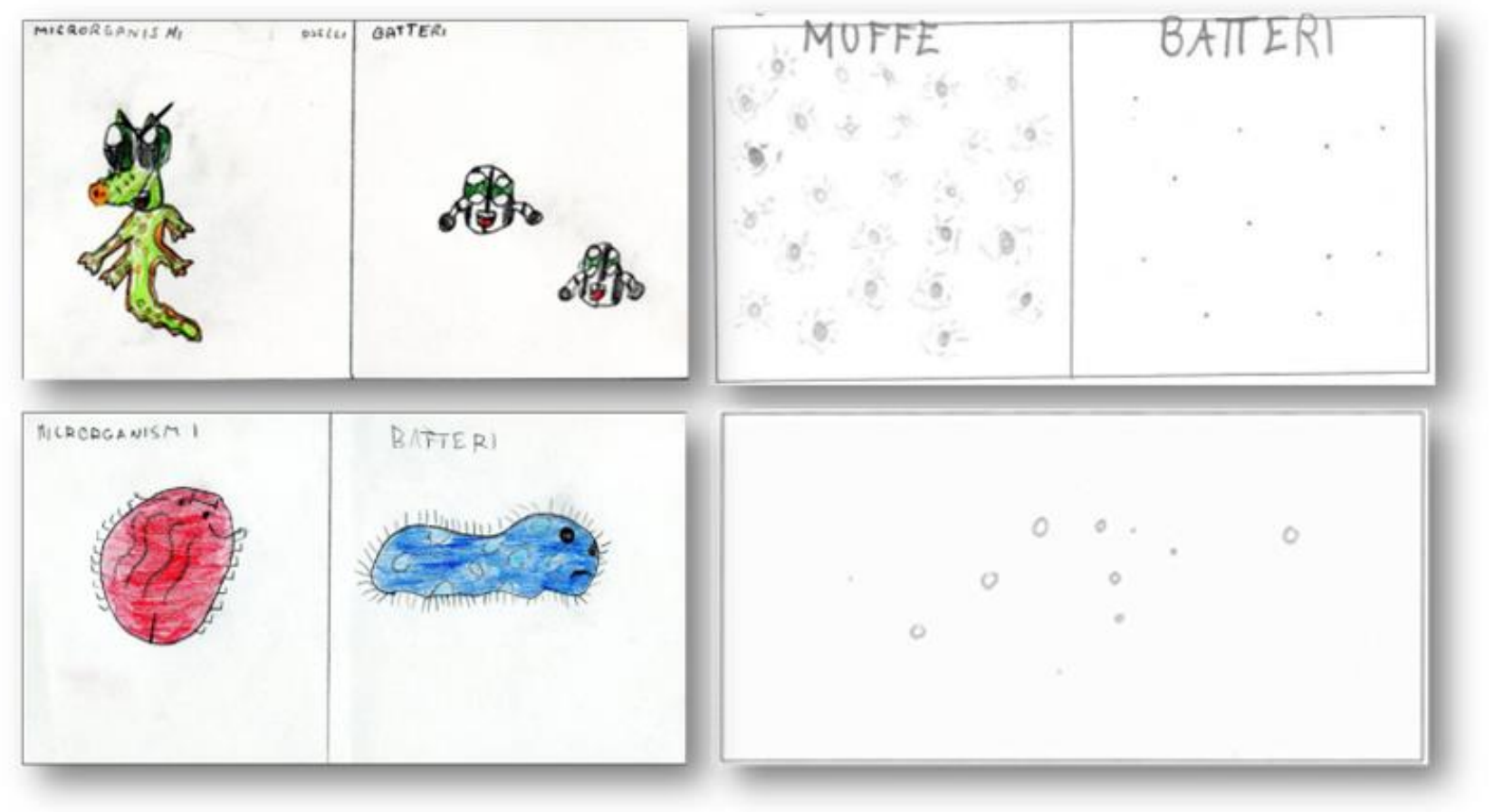

Fig. 3: Some children's drawings of the microorganisms and bacteria before and after the laboratory experience and the observation under the microscope.

\subsubsection{Results of the Second Step: Yeast, Proving and Fermentation}

For the lesson on yeasts the same method of the first step was used. A series of questions were addressed to the students to test their background knowledge like, for example, "Are there microorganisms in the kitchen? Are they helpful or harmful? Are there microorganisms that convert food? Which ones? What are yeasts? Where can we find them?"

Thanks to this process it was possible to enhance their knowledge on the subject introducing new concepts using examples taken from everyday life and, by the end of the lesson, everyone knew that yeasts were unicellular fungi. Students were also asked to draw a picture of yeasts and, this time, they did not represent microorganisms like small animals like they did in the previous laboratory, but, using their newly acquired knowledge, they drew yeasts as dots. This was a very important result because it helped us understand how useful it was for them to work in a laboratory during the previous experiment and how it had changed some of their concepts about microorganisms.

After the questions and a general explanation, the subject was introduced with a lesson in the classroom using a Power Point presentation. The focus of the slides was on the following issues: what are yeasts; their use in the food making process; the biochemical process of fermentation; what is leavening. The most difficult part was trying to explain the difference between the fermentation and the rising, that is the observable consequent phenomenon.

The second part of the activity was carried out in the Science laboratory and it was about the leavening of bread. The scientific method was used. Firstly, some questions were raised, questions like: "Why do we observe the phenomenon of leavening in bread making?"; "What is the role of yeast in leavening?"; "How does yeast make the bread rise?". The hypothesis developed by the students was that the leavening was caused by yeast and that, together with other ingredients, yeast makes the bread softer by inflating it. To test the hypothesis, it was necessary to do an experiment.

The students were divided into small groups, which were also provided with the necessary tools. They had three cups, named A, B and C. In every cup there were 4 teaspoons of flour, some water and a bit of yeast. 
On cup $B$ and $C$ there was also a teaspoon of sugar. After putting all the ingredients in the caps, the students have been asked to mix everything until the mixture had the consistency of a milkshake. The dough in every cup was then measured in weight and height and the data obtained were recorded in a special card, given to each student. It has to be noted that it would have been more appropriate to measure the volume of the dough and not the height, but, working with young students (8 years old) it was easier to let them simply measure the height with a ruler. However, it was carefully explained that it would be ideal to measure the volume of the dough instead of the height because it is the volume that increase after alcoholic fermentation, not the height itself. Weighing the mixture was really helpful because it allowed children to understand that the change in volume is due to the yeast gas production and the weight stays the same.

After the measurements, the cap A and B were placed over a basin of hot water, while the cap C was left on the table to rest for approximately 40 minutes. In the meanwhile, a bit of yeast was dilute in water and spread on a glass slide to observe it under the optical microscope. The students were asked to draw what they have observed. They all represented yeasts as pellets and they all noticed that yeasts, unlike bacteria, are larger and clearly visible under the microscope.

After 40 minutes, the students proceeded to observe the changes in the dough of the three cups. They weighted each cup and they measured the height of the dough. They observed and understood a few important concepts regarding yeasts and fermentation.

First of all they all understood the importance of the temperature. The dough in the cup B had the biggest volume and it was because it had the optimal condition of growth: a lukewarm temperature and the presence of sugar. Also the dough in the cup A was inflated but not as much as the one in cup B because in cap A there was no sugar and the yeasts had to split the complex sugars of the flour in order to grow and this is a longer process. In the cup $\mathrm{C}$ there was no visible growth because the temperature was so low that it inhibited the biochemical processes even in the presence of sugar.

Secondly they analysed the lack of change in the weight of the doughs even if there was a visible growth in volume. It was opened a discussion to talk about all the new concepts learnt and to explain in details how the process of fermentation creates the phenomenon of leavening and how, the carbon dioxide produced by yeast as a waste product of fermentation, makes the dough simply increase in volume, without changing its weight. To better explain this process to the students, a mixture of leavened bread was shown to them. They could see the gas bubbles on the surface and, when the dough was cut, they could also observe the gas bubbles inside.

\section{DISCUSSION}

In the World and the European scene, many studies analyzed the most significant approaches to improve the teaching of science (Gaiotto et al., 2013, 2020; Tonon et al., 2013, 2020; Pavan and Santovito, 2014; Zandonella Necca et al., 2014; Toninato and Santovito, 2015; Trevisan and Santovito, 2015; Gaiotto and Santovito, 2016; Rossi and Santovito, 2016; Capparotto et al., 2017; Favaron et al., 2017; Lago et al., 2017; Meneghetti et al., 2017; Barbacovi et al., 2018; Fassinato et al., 2018; Forlin et al., 2018; Grando et al., 2018a, 2018b; Tura et al., 2018; Chiesa et al., 2019; Gallina et al., 2019; Lui et al., 2019; Palmieri et al., 2019; Bortolami et a., 2020; Corbolino et al., 2020; Fabris et al., 2020; Zanata and Santovito, 2020). Nevertheless, these practices were found not to be used in Italian schools.

The focus of this particular study was the teaching of Microbiology using laboratory didactics and the scientific method, with a focal point on microorganisms like bacteria and yeasts.

One of the most peculiar characteristics of this work was that the activity was held in two third classes of the Primary School, while usually it is an activity for a more advance grade. The results showed that the topic was well understood and the students showed a great involvement and interest on it.

Another main objective of this study was to test the efficacy of laboratory didactics in the teaching of Life Sciences, in comparison with the traditional teaching methods. The same arguments were proposed using the two different methods. The results of the tests conducted after every activity showed how, in traditional teaching, knowledge is transmitted in a passive manner by teacher to the students. The students learn through a deductive method imposed by the teacher, which provides answers and solutions to problems. There is a constant dialogue with the textbook, on which the teacher bases his activities. Teaching is central and children's learning is relegated to the second place.

In the laboratory didactics, however, an inductive method is used. Thanks to it, students can discover firsthand the regularities, the rules and the constants of the problem analyzed and learn by discovery, they can build knowledge networks thanks to social interactions with peers and use the experience in their everyday life. Students are the protagonists of the learning process while the teacher acts as an indirect guide. 
In this project, the students were able to directly experience the differences between an educational approach that has provided them with notions already fixed and another in which they were able to observe, formulate hypotheses, compare, experiment and generalize. The results of the tests show how important it was for the student to use some instruments, like the microscope or to actively develop an experiment.

Moments of experimentation have been integrated with moments of reflection and discussion on what was happening, and this was fundamental to build shared knowledge. Another important process was the creation of a bridge that allowed the integration between everyday life and the laboratory experience, providing a solid foundation for a meaningful and lasting learning.

It was interesting to notice how the specific scientific terms were easier to assimilate if the students discovered them by themselves and not by reading a textbook.

Finally, drawing was used as another way to express knowledge and this has proved to be an excellent method to remember what was observed.

In conclusion, the laboratory didactics, the scientific instruments and the scientific method, with its observations, comparisons and experimentations, have proven to be of primary importance for a meaningful learning in Life Science teaching. It was also proved how all the activities, even the most complexed, can be taught to students of all ages with the appropriate adjustments and that Microbiology can be a subject suitable even to children of primary school.

Despite the absence of regulatory references in the national and regional intervention programs for dealing with Microbiology in Primary School, it is desirable that this discipline is increasingly addressed with children aged 6 to 10. Also from a didactic research point of view, which would favor the excess of possible criticalities, which did not emerge in the present experimentation, but which could obviously arise in other school contexts.

\section{REFERENCE LIST}

Barbacovi, V., Santovito, G. \& Irato, P. (2018) Little scientists for large discoveries: an experimental approach to survey the world with classes ii of the primary school - The observation and study of plant life. In: EDULEARN18 Proceedings, IATED, Valencia. https://doi.org/10.21125/edulearn.2018.1579

Bortolami, I., Bisaccia, P., Corrà, F., Bonato, M., Irato, P. \& Santovito, G. (2020) The blue gold: an empirical research to introduce the discussion of water issue in relation to plants, animals and human in primary school. In: EDULEARN20 Proceedings, IATED, Valencia, https://doi.org/10.21125/edulearn.2020.0496.

Capparotto, A., Bramuzzo, S., Callegaro, E., Poloni, E., Corrà, F. \& Santovito G. (2017) The didactics of biology in primary school: an innovative approach to skeletal system teaching in fifth class based on comparative vertebrate anatomy. In: INTED2017 Proceedings, IATED, Valencia. http://doi.org/10.21125/inted.2017.0935

Chiesa, E., Irato, P. \& Santovito, G. (2019) The circulatory system of vertebrates and invertebrates: an empirical research to introduce in the fourth class the treatment of animal morphology in a comparative key. In: INTED2019 Proceedings, IATED, Valencia. https://doi.org/10.21125/inted.2019.0391

Corbolino, N., Bisaccia, P., Corrà, F., Bonato, M., Irato, P. \& Santovito, G. (2020) The vegetable garden. an instrument for sustainable development education and care pedagogy. In: INTED2020 Proceedings, IATED, Valencia, https://doi.org/10.21125/inted.2020.1282.

Fabris, G., Bisaccia, P., Corrà, F., Bonato, M., Irato, P. \& Santovito, G. (2020) Discovering the nervous system. An innovative teaching approach for primary school. In: EDULEARN20 Proceedings, IATED, Valencia, https://doi.org/10.21125/edulearn.2020.0889.

Fassinato, C., Nicorelli, E., Corrà, F., Irato, P., Guidolin, L. \& Santovito G. (2018) An innovative approach to deal with biodiversity at school with its investigation in different environments. In: EDULEARN18 Proceedings, IATED, Valencia. https://doi.org/10.21125/edulearn.2018.0717

Favaron, A., Ancona, E., Bramuzzo, S., Callegaro, E., Guidolin, L., Irato, P. \& Santovito, G. (2017) An innovative teaching approach to circulatory and skeletal systems based on comparative vertebrate 
anatomy and physiology. In: EDULEARN17 Proceedings, IATED, Valencia. http://doi.org/10.21125/edulearn.2017.1015

Forlin, E., Santovito, G., Guidolin, L. \& Irato, P. (2018) Citrus fruits. Course to educate to scientific curiosity. In: EDULEARN18 Proceedings, IATED, Valencia. https://doi.org/10.21125/edulearn.2018.1573

Gaiotto, A., Tonon, S. \& Santovito, G. (2013) The scientific method in the teaching of life sciences in primary school, The plants and their seasonal changes". In EDULEARN13 Proceedings, pp. 4226-4235.

Gaiotto A., Santovito G. (2016) An innovative didactic approach to the study of invertebrate animals in primary school. In: EDULEARN16 Proceedings, IATED, Valencia. http://doi.org/10.21125/edulearn.2016.1284

Gaiotto, A., Bisaccia, P., Bonato, M., Irato, P., Corrà, F., Santovito, G. (2020) The plants and their seasonal changes: teaching biology in primary school using the scientific method. In: INTCESS2020 Proceedings, OCERINT, Istanbul, pp 261-270.

Gallina, S., Irato, P. \& Santovito, G. (2019) Inquiry into animal tracks: an experimental application of IBSE inquiry based science education- approach in the ecological field in primary school. In: INTED2019 Proceedings, IATED, Valencia. https://doi.org/10.21125/inted.2019.0089

Grando, G., Bramuzzo, S., Irato, P., Guidolin, L., Ferrari, L. \& Santovito, G. (2018) Introduction to the world of insects: a didactic research in kindergarten. In: INTED2018 Proceedings, IATED, Valencia. https://doi.org/10.21125/inted.2018.1066

Grando, G, Bramuzzo, S., Callegaro, E., Guidolin, L., Irato, P. \& Santovito, G. (2018) Who is afraid of insects? A didactic research in the biological field in kindergarten. In: EDULEARN18 Proceedings, IATED, Valencia. https://doi.org/10.21125/edulearn.2018.0724

Lago, A., Masiero, S., Bramuzzo, S., Callegaro, E., Poloni, E., Corrà, F. \& Santovito G. (2017) Exploring microbiology and biotechnologies: a laboratory approach to the study of yeasts and bacteria in primary school. In: INTED2017 Proceedings, IATED, Valencia. http://doi.org/10.21125/inted.2017.0992

Longo, C. (1998). Didattica della biologia, La Nuova Italia, Scandicci.

Lui, F., Irato, P. \& Santovito, G. (2019) Discovering living organisms: a didactic research to introduce biology in kindergarten. In: EDULEARN19 Proceedings, IATED, Valencia. https://doi.org/10.21125/edulearn.2019.1040

Meneghetti, G, Bramuzzo, S., Callegaro, E., Guidolin, L., Irato, P. \& Santovito G. (2017) The kingdom of fungi in primary school: an educational research in biology field. In: EDULEARN17 Proceedings, IATED, Valencia. https://doi.org/10.21125/edulearn.2017.1023

Palmieri, G., Irato, P., Nicolosi, P. \& Santovito, G. (2019) A day at the museum. Laboratory teaching in the Museum of Zoology at the University of Padua for primary school. In: EDULEARN19 Proceedings, IATED, Valencia. https://doi.org/10.21125/edulearn.2019.1037

Pavan, C. \& Santovito, G. (2014) The laboratory didactics in the teaching -learning processes of life sciences. an educational project on microorganisms in the alimentation in primary school. In: EDULEARN14 Proceedings, IATED, Valencia, pp 7546-7555.

Rossi, E. \& Santovito, G. (2016) Introduction to Mendelian genetics in primary school. In EDULEARN16 Proceedings, IATED, Valencia. http://doi.org/10.21125/edulearn.2016.1274

Toninato, V. \& Santovito, G. (2015) The laboratory didactics in the teaching-learning processes of life sciences. an educational project on the structure of the flower and the inflorescences phenomenon in primary school. In: EDULEARN15 Proceedings, IATED, Valencia, pp 2245-2254.

Tonon, S., Gaiotto, A. \& Santovito, G. (2013) The active teaching of life sciences in primary school: a comparative approach to the musculoskeletal system. In: EDULEARN13 Proceedings, IATED, Valencia, pp. 4289-4298.

Tonon, S., Bisaccia, P., Bonato, M., Irato, P., Corrà, F. \& Santovito, G. (2020) A comparative approach to the musculoskeletal system in primary school In: INTCESS2020 Proceedings, OCERINT, Istanbul, pp 251-260.

Trevisan, T. \& Santovito, G. (2015) Teaching evolution: a laboratory approach. In: EDULEARN15 Proceedings, IATED, Valencia, pp 2234-2244. 
Tura, N., Guidolin, L., Irato, P. \& Santovito, G. (2018) From cell to inheritance of characters: an introduction to classical genetics in primary school. In: INTED2018 Proceedings, IATED, Valencia. https://doi.org/10.21125/inted.2018.1076

Zanata, M. \& Santovito, G. (2020) The "Da Vinci" Biodiversity Park (Treviso, Italy). A didactic garden as innovative support to the teaching of science in secondary school. In: INTED2020 Proceedings, IATED, Valencia, https://doi.org/10.21125/inted.2020.1474.

Zandonella Necca, I., Tamino, G. \& Santovito, G. (2014) Sustainable food: an educational proposal, for key stage 3 in secondary schools, based on the assessment for learning method. In: EDULEARN14 Proceedings, IATED, Valencia, pp 7348-7356. 